\title{
ethic \\ ESPINOSA E HOBBES: CONSIDERAÇÕES SOBRE A DEMOCRACIA E A MONARQUIA
}

\author{
SPINOZA AND HOBBES: CONSIDERATIONS ON DEMOCRACY \\ AND MONARCHY
}

\author{
PATRICIA NAKAYAMA ${ }^{1}$ \\ (UNILA/Brasil)
}

\begin{abstract}
RESUMO
Este estudo pretende abordar o tratamento acerca dos regimes políticos em Espinosa e Hobbes, especialmente sobre a democracia e a monarquia. Em geral, o filósofo de Westport é tratado como oposto ao holandês quando o assunto é democracia, pelo qual o primeiro defenderia a monarquia absoluta e o outro, a democracia absoluta. Com o intuito de demonstrar este debate de ideias, além da argumentação dos próprios filósofos, faremos uma análise dos principais comentadores sobre as referidas temáticas, bem como dos contextos das principais fontes intelectuais. A reconstrução da recepção dos textos de Hobbes na Holanda do século XVII é tão sui generis que deve ser objeto de estudo tanto quanto os textos dos filósofos. Além do contexto holandês, resgataremos o contexto inglês buscando suas similitudes. A recepção dos textos hobbesianos na Inglaterra do século XVII, comparado à recepção contemporânea, configura uma contradição na questão das formas de governo, na qual o primeiro seria um Hobbes democrata e na segunda, um Hobbes monarquista absolutista. A partir do resgate das fontes antigas de Hobbes, em especial de Antifonte, é possível encaminhar a questão dos regimes políticos em Hobbes de um modo alternativo. A democracia e a monarquia em Hobbes, a partir desta ótica, não se excluem. São regimes possíveis e admitidos na constituição do poder soberano hobbesiano. Por fim, apresentaremos uma abordagem que lança novas luzes sobre estes estudos, demonstrando que Espinosa não antagoniza com Hobbes sobre a democracia.

Palavras-chave: Hobbes; Democracia; Espinosa; Antilogia; Monarquia
\end{abstract}

\begin{abstract}
This study aims to address the treatment about political regimes in Spinoza and Hobbes, especially about democracy and monarchy. In general, the Westport philosopher is treated as the opposite of the Dutch when the subject is democracy, whereby the first would defend absolute monarchy and the other, absolute democracy. In order to demonstrate this debate of ideas, in addition to the philosophers' own arguments, we will analyze the main scholars on these themes, as well as the contexts of the main intellectual sources. The reconstruction of the reception of Hobbes' texts in seventeenth-century Holland is so sui generis that it will be as much an object of study as the texts of the philosophers. In addition to the Dutch context, we rescued the English context looking for its similarities. The reception of Hobbesian texts in England in the 17th century, compared to the
\end{abstract}


contemporary reception, configures a contradiction in the question of forms of government, in which the first would be a democratic Hobbes and in the second, an absolutist monarchist Hobbes. From the rescue of ancient Hobbes sources, especially Antiphon, it is possible to address the question of political regimes in Hobbes in an alternative way. Democracy and monarchy in Hobbes, from this point of view, are not mutually exclusive. These are possible and admitted regimes in the constitution of the Hobbesian sovereign power. Finally, we will present an approach that sheds new light on these studies, demonstrating that Spinoza does not antagonize Hobbes about democracy.

Keywords: Hobbes; Democracy; Spinoza; Antilogy; Monarchy

\section{Introdução}

O presente estudo tem como principal hipótese apresentar uma nova perspectiva sobre um antagonismo muito presente quando se trata de Hobbes e de Espinosa: o inglês seria o ideólogo das monarquias absolutistas e o holandês o defensor da democracia. ${ }^{2}$ Conforme nossa pesquisa, Hobbes não seria exatamente um partidário dos realistas, embora sua obra permita esta leitura. Encontramos, numa rápida revisão bibliográfica sobre o tema da democracia e da monarquia em Hobbes, uma recepção diametralmente oposta. Embora, na contemporaneidade, seja mais difundida a visão de um Hobbes monarquista, no século XVII o filósofo inglês foi recebido predominantemente como um inspirador dos democratas radicais de seu tempo. Este estudo não pretende defender a filiação de Hobbes à monarquia ou à democracia, mas somente demonstrar como estes dois aspectos são constitutivos de sua filosofia, não conformando um problema teórico de contradição, mas sim, uma antilogia. Deste modo, veremos como Espinosa não seria exatamente um antagonista da tese hobbesiana sobre a monarquia. Ambos concordariam sobre as teses democráticas, discordando em outros aspectos fundamentais.

Para apresentar esta hipótese, na primeira seção trataremos do contexto holandês, a fim de compreender posteriormente a seção seguinte, a recepção dos textos hobbesianos por Espinosa, bem como seu entendimento sobre a monarquia e apologia da democracia. Num terceiro tópico, passaremos à recepção dos textos hobbesiano no século XVII, bem como sua interpretação como defensor da monarquia e, na sequência, passaremos aos textos de Hobbes sobre a democracia e o tratamento dado ao elogio da monarquia. No último tópico antes da conclusão, buscaremos elucidar como Hobbes se apropria da antilogia grega de Antifonte, de modo a incorporar o antagonismo entre democracia e monarquia em sua filosofia. Após esta trajetória, consideramos ter elementos suficientes para abordar 
como Espinosa e Hobbes não são opostos em seus entendimentos sobre a democracia.

\section{Aspectos do contexto holandês: sobre o "cartesianismo hobbesiano"}

Ao nos debruçarmos sobre as ideias políticas de Espinosa, não raro as imagens sobre a vida civil suscitam a presença da filosofia hobbesiana. A obra política de Hobbes impactou fortemente a vida intelectual na república holandesa, em meados do século XVII. O hobbesianismo holandês floresce juntamente, configurando-se como parte, de um tipo de cartesianismo na Holanda. Em outras palavras, este cartesianismo holandês sui generis, fenômeno único na Europa, não era composto exclusivamente pelas obras cartesianas, mas por uma mistura de ideias de Descartes e Hobbes (NYDENBULLOCK, 2007, 6). Henricus Regius e Gerard Wassenaar, da Universidade de Utrech, foram importantes representantes deste cartesianismo que recebeu com igual fervor as ideias políticas de Hobbes. Lambertus van Velthuyesen, ${ }^{3}$ foi autor de defesas de Descartes, Copérnico e Hobbes. Em seu prefácio do De Cive, Lambertus defendeu o trabalho hobbesiano como se fosse uma empreitada cartesiana (MALCON, 2008, 547). A tradução para o holandês do Leviatã data de 1667 e uma importante coleção latina sobre a obra de Hobbes foi publicada na Amsterdam em 1668 (MALCON, 2008, 545). É muito provável que Espinosa tenha tido acesso a uma versão manuscrita do Leviatã traduzido para o holandês por Abraham van Berckel e sabe-se que ele possuía uma edição latina do De Cive (NYDEN-BULLOCK, 2007,1 ). Espinosa possuía obras de Van Velthuyesen (NYDEN-BULLOCK, 2007, 7), além de ser seu correspondente em algumas cartas. ${ }^{4}$ Não é espantoso, dentro deste contexto, encontrarmos tantas semelhanças entre Hobbes e Espinosa no campo político, especialmente no campo dos regimes políticos. Por outro lado, essas semelhanças apontam para caminhos distintos especialmente em seus fundamentos. Este estudo pretende apontar estas similitudes e diferenças especialmente no que tange à democracia e à monarquia, de modo a problematizar esta discussão. Dentre os principais comentadores da obra dos referidos filósofos, Espinosa e Hobbes são apresentados como antagônicos quando a questão é regime político. Espinosa seria o defensor da democracia e Hobbes seria o apologeta da monarquia. Nossa hipótese de trabalho pretende demonstrar que tal recepção dos textos hobbesianos reside neste cartesianismo sui generis e portanto, não se configura como visões antagônicas acerca dos regimes políticos. 


\section{Sobre o Hobbes de Espinosa}

Um holandês proeminente deste círculo de cartesianos, muito próximo a Espinosa, foi Franciscus van den Enden. Segundo Nyden-Bullock $(2007,9)$, Van den Enden tinha uma escola alternativa, onde era possível aprender latim, literatura clássica, filosofia, a nova filosofia e ciência. Sabese que Espinosa viveu com Van den Enden em $1656,{ }^{5}$ onde aprendeu latim e foi introduzido nos trabalhos de Grocio, Maquiavel e Hobbes. A recepção dos textos de Hobbes em muito nos interessa, pois pareceu ter um grande impacto no pensamento de Espinosa.

É notável a intensa trajetória política de Van den Enden, um exímio leitor do Leviatã. Em 1661 é solicitado por Pieter Cornelisz Plockhoy ${ }^{6}$ a colaborar para a formação uma colônia democrática baseada nos princípios do Colegiado na Nova Holanda (em um assentamento ao longo do rio Delaware). Van den Enden desenvolve um conjunto de cartas que foi publicado em 1662, intitulado Kort Verhael van Nieuw-Nederlandts (Uma breve narrativa da Nova Holanda). Dentre suas obras, seu principal trabalho político foi Vrye Politijke Stellingen, en Considertaien van Staat, gedaen na der ware christenens even gelijke vryheits grondern; strekkended tot een rechtschape, en ware verbeteringh van staat, en kerk (Propostas políticas libertárias e Considerações sobre o Estado, baseados nos verdadeiros princípios cristãos de liberdade igualitária, para um aperfeiçoamento justo e verdadeiro do Estado e da Igreja), publicado em 1665. Além de escritor, também se envolveu em práticas políticas que hoje denominaríamos como revolucionárias. Van den Enden esteve na França em 1670, onde participou em uma conspiração para derrubar a monarquia (NYDEN-BULLOCK, 2007, 10).

Em seu Vrye Politijke Stellingen, é notória a presença de Hobbes, a partir de uma leitura do Leviatã pouco conhecida em nossos meios, embora muito disseminada no século XVII. Trata-se de uma recepção das obras de Hobbes em que o commonwealth hobbesiano é defensor da igualdade e da liberdade, valendo-se de suas metáforas sobre males e remédios ao corpo político, tema que será retomado por Espinosa cerca de dez anos depois em seu Tratado Político:

Nesse caso, se quisermos nos manter nos primeiros princípios, devemos primeiro examinar se eles são bons e se estão de acordo com os princípios de igualdade e liberdade; caso contrário, podemos destruí-los todos rapidamente, levianamente e remetê-los para o nosso maior proveito: porque poupar cidadãos sem calma e de forma incompetente 
será sempre considerado tão ingênuo ou estúpido que, mesmo que bem proposto, não preferirá ajudar e aniquilar tudo que contrasta com os princípios de liberdade e de igualdade. $\mathrm{E}$ eu considero isso não apenas como o único remédio certo para todos os males civis, mas também como o único terreno seguro e inabalável para um império eterno ou um Commonwealth ${ }^{7}$ (VAN DEN ENDEN apud KLEVER, 2016, 13. Tradução nossa).

A filosofia política de Espinosa porta fortes traços do pensamento de Van den Enden. A severa crítica aos oponentes da liberdade, são expostos principalmente no capítulo IX do Tratado Político, principalmente por causarem danos de origem intestina a uma sólida constituição republicana. Isto significa afirmar também que, para libertar o commonwealth de guerras civis, o que seria a morte do Leviatã, é necessário atentar para este quesito. Espinosa cita um exemplar episódio das Guerras Púnicas, na qual quando os romanos deliberam, a cidade de Sagunto perece $e$ analogamente, "quando poucos decidem somente a partir de sua paixão, perece a liberdade e o bem comum." (ESPINOSA, 1882, 358. Tradução nossa). ${ }^{8}$ Ou seja, quando a minoria delibera, a cidade perece e, analogamente, quando a maioria delibera, floresce o bem comum e a liberdade.

A partir destes princípios, o da liberdade e da igualdade, Espinosa desenvolve um minucioso estudo, infelizmente não finalizado, sobre os três regimes clássicos, a saber: monarquia, aristocracia e democracia. ${ }^{9}$ Todos são considerados legítimos e o filósofo nos apresenta quais seriam suas melhores formas para se manter a igualdade e a liberdade. Conforme apontamos no início, aqui trataremos somente da democracia e da monarquia. A melhor monarquia é aquela na qual a multidão conserva uma ampla liberdade e uma igualdade no que toca ao poder monárquico. Segundo Espinosa:

Concluímos, portanto, que a multidão pode conservar sob um Rei uma ampla liberdade, de maneira completa, se o poder do Rei se determinar pelo poder da própria multidão, e a sua proteção seja proveniente da própria multidão. É a única regra que segui ao definir os princípios fundamentais de um Império monárquico (ESPINOSA, 1882, 330. Tradução nossa). ${ }^{10}$

Para tratar da democracia, tomaremos a análise feita no Tratado Teológico Político, pois ali se encontra melhor concluída que no Tratado político. ${ }^{11}$ No Tratado Político, a democracia ${ }^{12}$ é o último regime a ser mencionado. O estudo é inconcluso, mas assim como a análise da 
aristocracia e da monarquia, o princípio aplicado segue sendo a questão da igualdade e da liberdade. No Tratado Teológico Político a democracia é o primeiro regime a ser apresentado, pois, segundo Espinosa, ele é o que mais se aproxima da liberdade que a natureza oferece a cada um (ESPINOSA, 2004, 332). Por este motivo, segundo Espinosa, a democracia é considerada como o melhor regime para a manutenção da estabilidade política.

Em democracia, com efeito, ninguém transfere o direito natural para outrem ao ponto de este nunca mais ter de o consultar daí em diante: transfere-o, sim, para a maioria do todo social, de que ele próprio faz parte, e nessa medida, todos continuam iguais, tal como acontecia anteriormente no estado de natureza (ESPINOSA, 2004, 332).

Apresentado o contexto e as linhas gerais que ser-nos-ão relevantes acerca da recepção de Hobbes em Espinosa, passemos à recepção de Thomas Hobbes.

\section{A recepção de Hobbes no século XVII: democrata e igualitário}

Como afirmamos linhas acima, a recepção das obras hobbesianas por Van den Enden, no século XVII, estavam de acordo com a maioria dos leitores de seu tempo. Muito se conjecturou sobre estas ideias democráticas contidas nas obras de Hobbes, especialmente no Leviatã. Houve rumores de que o inglês havia se dedicado a escrever uma obra em defesa da democracia pois pretendia retornar à Inglaterra, que se encontrava sob o governo o Parlamento desde 1651, após a derrota de Carlos I, deposto pelos exércitos liderados por Cromwell. Isto não era verdade, visto que as principais ideias do Leviatã, consideradas democráticas, já estavam presentes no Elementos da Lei, de 1640. Por este motivo, resta evidente que não era intenção de Hobbes posicionar-se ao lado dos parlamentaristas. Além do que, anos depois que chegou da França, Hobbes foi banido da corte inglesa. Segundo Gooch, ele teria sido expulso não por motivos políticos, mas teológicos, sobretudo por causa das suas críticas às pretensões eclesiásticas (1939, 281). É importante recordar que, no século XVII, ser banido por ateísmo é também ser banido por questões políticas. Suas ideias anticlericais já estavam em circulação desde 1642 com o De Cive. O próprio Gooch $(1939,281)$ menciona que sua obra, o Leviatã, fora "escrito em defesa do título de Oliver". ${ }^{13}$ A declaração de Sir Edward Nicholas, o secretário do Rei, atesta o banimento de Hobbes da corte inglesa: "Todos 
os homens honestos aqui estão muito satisfeitos que o rei, ao final, tenha banido de sua corte aquele pai dos ateus Sr. Hobbes." (SIR EDWARD NICHOLAS apud GOOCH, 1939, 28. Tradução nossa). ${ }^{14}$

Em seu Leviatã, Hobbes defendeu outra tese igualmente criticada, na qual os homens nascem iguais por natureza (HOBBES, 1997, 107). A igualdade entre os homens tinha como consequência a inexistência do direito divino e a abolição do direito hereditário, orbitando seu direito terreno em torno do soberano absoluto, seu Deus mortal. O historiador britânico marxista Christopher Hill também afirma que: "No plano intelectual, Hobbes muitas vezes se situou junto aos radicais" (HILL, 1991, 369).

O conde de Clarendon ${ }^{15}$ considerava que "Hobbes não valia mais que um leveller, dada sua crença na igualdade entre os homens e a sua convicção de que a ascensão social devia estar aberta a talentos." (Clarendon citado por Hill, op. cit., 369). A polêmica ocorria em meio a uma situação histórica muito particular. Leveller, qualidade atribuída a Hobbes pelo Conde, era um dos movimentos mais radicais da Guerra Civil Inglesa. Seu nome era derivado do verbo to level, em português nivelar, pois eram desejosos da igualdade das condições sociais. Quando Hobbes afirma que "a natureza fez os homens tão iguais quanto às faculdades do corpo e do espírito" (HOBBES, 1997, 107), que a cidade é formada pela concórdia de cada um na multidão, concordando com os demais "que, nos assuntos que qualquer um propuser à assembleia, ele aceite o que for aprovado pela maior parte como constituindo a vontade de todos" (HOBBES, 1998, 2) e, sobretudo, que "sem mútua aceitação não há pacto possível" (HOBBES, 1997, 118), evidencia-se a possibilidade de uma leitura a partir de uma perspectiva muito próxima a dos levellers.

Influente poeta inglês panegirista do Rei contemporâneo de Hobbes, em suas Considerations upon the reputation of Thomas Hobbes, ${ }^{16} \mathrm{Sir}$ William Davenant considerou Hobbes como responsável pelo levante escocês que instituiu o presbiterianismo escocês de inclinação calvinista, movimento contrário ao catolicismo e que assegurou um maior poder ao Parlamento. Este movimento foi denominado The Convenanters (Os Convencionadores). Estes assim foram nomeados em função de erigirem uma convenção, na qual prescreviam a manutenção da doutrina e da política presbiteriana (notadamente democrática) como única forma religiosa na Escócia. Seu primeiro documento data de dezembro de 1557. A Convenção, citada na acusação de Davenant $(1966,418)$, remete a este movimento quando da ocasião em que este associa-se ao Parlamento inglês para derrubar o Rei Carlos I. Em 1643 os Covenanters escoceses foram 
solicitados pelo Parlamento inglês a enviar auxílio bélico contra as tropas monarquistas.

Como se trata de um movimento anterior a Hobbes, tal responsabilização não pode ser considerada verdadeira, ${ }^{17}$ mas certamente é possível reconhecer a ideia de convenção em Hobbes. Especialmente no Leviatã, veremos que a noção de convenção, ${ }^{18}$ evidentemente sobre outros parâmetros, é mencionada em muito de seus capítulos.

Outro movimento sedicioso também considerado por William Davenant como de responsabilidade de Hobbes, foi o Engagement. Engagement era a expressão que denominava os defensores do novo poder nos primeiros meses de 1649 na Inglaterra. Sua linha argumentativa baseava-se no engajamento junto ao Parlamento através da obediência ao novo regime.

Aquela mesma associação que resultou na Convenção [Covenant] junto à nação Escocesa contra o Rei, é por si só um crime grandíssimo, e tu [Thomas Hobbes] és o culpado. E igualmente foi a imposição do Engajamento [Engagement], do qual tu também és culpado, tal como está sendo feito pelo então Parlamento, cujos princípios democráticos tu aprovas (DAVENANT, 1966, 418. Tradução nossa). ${ }^{19}$

Há ainda outros documentos que atestam a presença de Hobbes nas obras dos radicais de seu tempo, mas cremos ser suficiente o apresentado. Fora da Inglaterra, em seu tempo também, houve quem leu Hobbes como apologeta das monarquias. Em nossa pesquisa encontramos somente Descartes. Além de defensor dos reis, o francês considerou Hobbes autor de princípios e máximas muito perigosas e maldosas. Passemos às palavras de Descartes, que escreveu a um jesuíta sobre Hobbes, em 1643.

Tudo o que posso dizer do livro De Cive, é que julgo que seu autor é o mesmo que faz as Terceiras Objeções contra minhas Meditações, e que o encontro muito mais hábil em Moral que em Metafísica e Física; Não obstante eu não possa de nenhum modo aprovar seus princípios nem suas máximas, que são muito maldosas e muito perigosas, nas quais se supõe que todos os homens [são] maus, ou dá-lhes propósitos para ser. Todo o seu objetivo é escrever em favor da Monarquia. (DESCARTES apud SCHUHMANN, 1998, 80. Tradução nossa). ${ }^{20}$ 
Além de Descartes, Carl Schmitt (1938), Joseph Vialatoux (1952), George P. Gooch (1939), Hugh Redwald Trevor Roper (1957), John W. N. Watkins (1965) e Marilena Chaui (2003) possuem teses importantes na historiografia que observam em Hobbes o ideólogo do absolutismo monárquico. Há muitos outros, mas em geral são seguidores teóricos destas célebres e importantes interpretações. Passemos agora aos textos de Hobbes, para compreendermos como as duas teses antagônicas sobre democracia e monarquia são igualmente constitutivas de sua filosofia.

\section{Thomas Hobbes, democracia ou monarquia}

A democracia em Hobbes é explicada no De Cive em termos numéricos quando justaposta aos outros regimes e é definida como aquele regime cujo poder reside num conselho, no qual todo cidadão tem direito a votar. Já a monarquia ocorre quando a autoridade suprema repousa num só (HOBBES, 1998, 119). Em Elementos da Lei, Hobbes explicita melhor o funcionamento da democracia, através do princípio de governo da democracia, o demos. O povo (demos), como pessoa artificial, segundo Hobbes, só existe dentro do contexto das assembleias. Findadas as sessões, não mais existe o povo. Aquele membro eleito pelo povo não passa de mais um da multidão tão logo acabe a reunião, que deve ter horário, uma pauta e esclarecimentos sobre as votações. Mesmo que as pessoas designadas pelos súditos para representá-las estejam sentadas na sala de votação e discutam sobre alguma lei e seu acordo seja unânime, elas não possuem o poder de deliberar pois não passam de multidão caso já tenha terminado a sessão (HOBBES, 19--, 161). Hobbes, assim como Espinosa, mantem o estado de natureza, na figura da multidão, presente em todos os regimes e especialmente na democracia. Sobre a monarquia, consideramos ser bastante disseminada a visão hobbesiana sobre o tema. Por este motivo, não a apresentaremos aqui a defesa detalhada que Hobbes faz da monarquia, mencionaremos somente afirmação de que "a monarquia tem proeminência sobre a democracia e a aristocracia." (HOBBES, 1998, 157). Tal afirmação encontra-se onde se concentra o elogio da monarquia, no capítulo $X$ de seu livro Do Cidadão (De Cive). O que segue são passagens menos conhecidas desta mesma obra sobre a crítica da monarquia.

As primeiras páginas do De Cive apresentam uma Epístola Dedicatória ao conde William de Devonshire, seu antigo pupilo, cuja abertura conta uma passagem da história romana na qual o povo, oprimido pela tirania dos Tarquínios, dizia que todos os reis deveriam ser incluídos entre os animais de rapina, segundo Catão. Após relatar este episódio da história romana, Hobbes pergunta-se se, deste modo, não estaria o povo comportando-se 
como fera rapace? Mas logo em seguida, quando o leitor poderia crer ser uma pergunta retórica, Hobbes coloca a possibilidade de Catão estar correto e cita Pôncio Telesino, um general que marchou sobre Roma, alegando destruir a floresta em que viviam os lobos e predadores da liberdade. Afirma Hobbes, mais adiante que, "para ser imparcial", ambos os ditos são posições corretas, e eis que aparece a famosa sentença (que não é de Hobbes e mas de Plauto) "que o homem é um deus para o homem, e que o homem é o lobo do homem" (HOBBES, 1998, 3), alegando ser a primeira sentença sobre a relação dos cidadãos entre si e a segunda, sobre a relação das cidades entre si, no caso contemporâneo, dos países (que vivem em estado de natureza, sem um soberano sobre o plano internacional segundo Hobbes). Ainda, no final da dedicatória, há uma passagem em que Hobbes endossa a necessidade de obediência a um governo aristocrático ou democrático, tal qual o monárquico, porque embora tenha se empenhado em fazer os homens acreditarem ser mais cômoda uma monarquia, no capítulo $X$ ele mesmo afirma que os argumentos não foram demonstrados.

Não dar ocasião a pensarem que minha opinião seja que se deve menos obediência a um governo aristocrático ou democrático, do que uma monarquia; pois, embora eu me haja empenhado pela argumentação de meu capítulo décimo a fazer os homens acreditarem que a monarquia é o mais cômodo dos governos (única coisa neste livro inteiro que confesso não ter sido demonstrado, mas apenas enunciada segundo a probabilidade) afirmo, porém, a todo momento, expressamente, que em qualquer tipo de governo deve haver um poder supremo e igual (HOBBES, 1998, 20. Grifo nosso).

O fato de não ser demonstrável, no século XVII e na filosofia hobbesiana, é o mesmo que dizer que são palavras vazias, pois não são deduzidas de princípios válidos. Hobbes de fato cumpre seus desígnios, não menciona, fora deste capítulo $X$, qualquer defesa da monarquia. Admitir que Catão estava correto, bem como assumir que os seus argumentos em favor da monarquia não foram suficientemente demonstrados, também pode ser lido como uma concordância com Catão e que Hobbes não considerava de fato como verdadeiros os argumentos favoráveis à monarquia frente aos outros regimes. Sobre esta conclusão, em que "qualquer tipo de governo deve haver um poder supremo e igual" de fato contradiz o elogio da monarquia, o governo de um, o elogio da desigualdade. Convém lembrar que, mesmo quando Hobbes faz o elogio da desigualdade na monarquia, a 
palavra desigualdade sempre vem acompanhada de consentida (HOBBES, 1998, 158).

Ainda sobre o poder supremo e igual, constatamos que esta enunciação acendeu em muitos a chama da igualdade. Em muitos momentos é possível interpretar o De Cive como um panfleto democrático, como na passagem da origem das cidades:

Devemos observar, a seguir, que cada um da multidão - a fim de que possa ter origem a cidade - precisa concordar com os demais em que, nos assuntos que qualquer um propuser à assembleia, ele aceite o que for aprovado pela maior parte como constituindo a vontade de todos. (...) E, se algum não consentir, apesar disso os demais constituirão a cidade entre si e sem ele (HOBBES, 1998, 102).

Uma outra afirmação bastante polêmica deste mesmo livro é que em qualquer governo, é o povo quem governa. Tal assertiva foi também muito bem recebida dentre os defensores da democracia, ainda que o capítulo $X$ dissesse exatamente o contrário.

Em qualquer governo é o povo quem governa. Pois até nas monarquias é o povo quem manda (porque nesse caso o povo diz sua vontade através da vontade de um homem), ao passo que a multidão é o mesmo que os cidadãos, isto é, os súditos. Numa democracia e numa aristocracia, os cidadãos são a multidão, mas o povo é a assembléia governante (the court). E numa monarquia os súditos são a multidão, e (embora isso pareça um paradoxo) o rei é o povo (HOBBES, 1998, 190).

Estas passagens supracitadas, além de muitas outras, como vimos no tópico anterior, possibilitaram a recepção de um Hobbes muito parecido com o de Espinosa e de Van den Enden, seu mestre.

Por outro lado, embora tenha afirmado o contrário, Hobbes não observa a igualdade entre os homens como um bem em si mesmo. No Leviatã encontramos esta condição como insegura. Tratar-se-ia da guerra de todos contra todos, portanto, uma "miserável condição em que o homem realmente se encontra, por obra da simples natureza" (HOBBES, 1997, 110), na qual não há perspectiva de futuro. Muitas vezes, amparados por estas ideias, a recepção que definiu Hobbes como monárquico encontra suas bases. Mas no capítulo seguinte, afirma o filósofo que a natureza manda buscar a paz. No capítulo XV, logo encontramos o Hobbes apologeta das leis naturais e mostra que é uma lei da própria natureza que os "homens cumpram os pactos que celebrarem" (HOBBES, 1997, 123). Ora, novos 
pactos entre os homens podem edificar novos governos e mundos completamente diferentes, tudo isso por ditame da natureza e aí encontramos novamente o Hobbes democrata e crítico da monarquia. Hobbes, por outro lado, não recomenda a conquista da soberania pela rebelião. Embora possa ser "coroada de êxito", é contrária à razão, pois "ao fazê-lo se ensina aos outros conquistar da mesma maneira" (HOBBES, 1997, 125). Mas, não obstante, a revolução pode ser coroada de êxito. O leitor parece não compreender tantas incoerências, mas o fato é que Hobbes entende que seu Leviatã, seu Deus mortal, pode ser uma democracia ou uma monarquia. Para o inglês, não importa tanto o regime, mas a concórdia e a obediência.

Em todas as passagens do Leviatã, quando vai se referir ao poder soberano, Hobbes sempre enfatiza que este pode ser uma assembleia ou um único homem, o monarca. Em se tratando de um poder absoluto, no caso de uma democracia, ela também constituir-se-á absolutamente tanto quanto uma monarquia.

Diz-se que um Estado foi instituído quando uma multidão de homens concordam e pactuam, cada um com cada um dos outros, que a qualquer homem ou assembléia de homens a quem seja atribuído pela maioria o direito de representar a pessoa de todos eles (ou seja, de ser seu representante ), todos sem exceção, tanto os que votaram a favor dele como os que votaram contra ele, deverão autorizar todos os atos e decisões desse homem ou assembléia de homens, tal como se fossem seus próprios atos e decisões, a fim de viverem em paz uns com os outro e serem protegidos dos restantes homens (HOBBES, 1997, 145. Grifos nossos).

Esta contradição é constitutiva da filosofia hobbesiana. Esta concepção tem suas raízes na antilogia de Antifonte, como veremos a seguir.

\section{Hobbes e a lógica antilógica 21}

A palavra antilogia (antilogía) porta uma anti logia, um discurso (logos) que se opõe ao outro, uma contradição, em latim, uma controversia. Tucídides $^{22}$ empregou a antilogia em sua História da Guerra do Peloponeso, tomada de seu mestre Antifonte, ${ }^{23}$ ao descrever os dois lados da guerra do Peloponeso sem tomar partido de lado algum. Sabemos que Hobbes foi um grande admirador de Tucídides e um de seus célebres tradutores. ${ }^{24}$ 
Antifonte, por seu turno, traz a arte de contrapor até em seu nome (anti phoné: fala contrária).

Antifonte de Ramnunte é mencionado por Hobbes no prefácio de sua tradução da Guerra do Peloponeso (HOBBES, 1966). Este fato é interessante na medida em que evidencia o contato de Hobbes com os fragmentos de Antifonte. No século XVII ainda não estava estabelecida a autoria dos textos de Antifonte, mas isso não se configurou exatamente como um problema para Hobbes. Tudo indica que o inglês descobriu três séculos antes que se tratava dos textos do mesmo Antifonte pelo fato de ter incorporado a antilogia em sua filosofia.

Por décadas discutiu-se sobre a existência de dois Antifontes, um orador e outro sofista e somente no século XX a historiografia concluiu que se tratava de um mesmo autor. Esta imprecisão se deveu ao fato de sua obra ser interpretada, assim como a de Hobbes, de maneira antagônica, ora defensor da igualdade e da democracia ora defensor da desigualdade ou ainda como antidemocrata. Consideramos que Hobbes, assim como Antifonte, não considerava que a expressa contradição era um problema. 0 problema maior era o estilhaçamento do poder soberano.

Há muitas semelhanças entre Hobbes e Antifonte. Antifonte foi criticado por seus companheiros aristocratas mais tradicionais (VIDAL, 2004, 78), assim como Hobbes. Vidal, estudioso de Antifonte, afirma que a passagem na qual Antifonte fala sobre a igualdade dos homens em geral foi mal lida pelos modernos. A recepção moderna observou nestas passagens a igualdade de direitos, porém Antifonte reconhecia que os homens são iguais por natureza, mas diferentes em seus costumes ou leis (VIDAL, 2004, 74).

Segundo Vidal $(1998,42)$, o líder oligarca e antidemocrático em nada se assemelhava com o sofista autor de Acerca da Verdade, na qual defendia a unidade do gênero humano igualando gregos e bárbaros, um homem inspirado em autênticos princípios democráticos. O fragmento abaixo parece ter inspirado a Hobbes sobre seu estado de natureza igualitário.

Conhecemos e veneramos, as dos que moram longe nem conhecemos nem veneramos. Agimos como bárbaros uns em relação aos outros, enquanto por natureza todos em tudo nascemos igualmente dispostos para ser tanto bárbaros quanto gregos. É o caso de observar as coisas que por natureza são necessárias a todos os homens: a todos são acessíveis as mesmas capacidades, e em todas essas coisas nenhum de nós é determinado nem como bárbaro nem como grego. Pois todos respiramos o ar pela boca e pelas narinas (ANTIFONTE, 2008, 77). 
Sobre este fragmento de Antifonte, Gagarin acredita que uma leitura mais adequada seria a que observa a criação de uma identidade Gregobárbaro, uma ambivalência (GAGARIN, 2001, 180). Para nossos propósitos, notamos uma relativização do ser grego a partir da condição humana, ou seja, uma reflexão sobre a ação dos gregos para com outros povos, um abandono das leis e um retorno à natureza. Em outras palavras, fora de nossa cidade, há uma situação de estado de natureza, onde o homem é o lobo do homem. Isso ocorre porque, segundo nossa percepção, importa a condução do leitor pelas sentenças construídas e as reflexões que elas provocam. As sentenças induzem o leitor a observar-se de outra maneira, a raciocinar acerca de sua própria condição, para finalmente constatar, com Antifonte, que somos bárbaros e gregos, porque somos iguais em nossas ações e condições, mas não somos iguais, pelos costumes. Se o leitor é um partidário do helenismo, dos gregos, ao ver-se na condição de humano, que é a de respirar pela boca, pelas narinas e simultaneamente na condição de grego, não venera os que moram longe, os estrangeiros bárbaros. Deste modo conclui o grego que é igual a qualquer outro ser humano. Dada esta igualdade, constata também que pode ser bárbaro para os que moram longe de Atenas. Segundo Vidal, igualdade por natureza e desigualdade por costumes não se opõem em Antifonte (VIDAL, 1998, 49). Se o leitor não é grego, ele se reconhece analogamente, na ocasião em que os gregos também são bárbaros para eles. A desigualdade também é reconhecida, por ambos, uma vez que tanto gregos quanto bárbaros não reconhecem nem veneram os costumes dos que moram longe. Ambos chegam à mesma conclusão, a esta relativização, a esta concórdia. Cremos que Antifonte, na medida em que provoca este sentimento de dissenso entre os povos, conduz a uma igualdade de sensação sobre a universalidade do ser estrangeiro, entre todos os leitores, sejam bárbaros ou gregos, a partir de suas desigualdades. Em outras palavras, a partir do dissenso se produz o consenso. O objetivo é conduzir o leitor a um ponto de concórdia, tal como pretendeu Hobbes com monarquistas e parlamentaristas em seu Leviatã.

Em Hobbes encontramos ainda a ideia que os homens são iguais por natureza. Esta igualdade se demonstra de modo antilógico, a partir do antagonismo entre forte e débeis fisicamente. A astúcia do débil compensa a falta de força física

A natureza fez os homens tão iguais quanto às faculdades do corpo e do espírito que, embora por vezes se encontre um homem manifestamente mais forte de corpo, ou de espírito mais vivo do que outro, mesmo assim, quando se considera 
tudo isto em conjunto, a diferença entre um e outro homem não é suficientemente considerável para que qualquer um possa com base nela reclamar qualquer benefício a que outro não possa também aspirar, tal como ele. Porque [...] mais fraco tem força suficiente para matar o mais forte, quer por secreta maquinação, quer aliando-se com outros que se encontrem ameaçados pelo mesmo perigo (HOBBES, 1997, 107).

Apesar de suas diferenças antagônicas, débeis e fortes são iguais em condições por natureza porque ambos são fonte de temor: os débeis são tão ameaçadores quanto os fortes, uns em relação aos outros. Fortes e débeis conformam uma condição de ambivalência antilógica.

Hobbes e Antifonte ainda guardam muitos outros paralelos que não trataremos aqui. Destacamos aqui somente a ideia da necessária concórdia civil. Ainda que pressionado pelas desordens de seu tempo, Hobbes nos mostra que o pior dos mundos é a Guerra Civil, a morte do Leviatã. Antifonte também chegou à mesma conclusão em sua obra intitulada $D a$ concórdia (FILÓSTRATO, apud PINTO, 2005, 225). Esta obra, da qual nada restou e que conhecemos apenas pela doxografia de Xenofonte, endossa a afirmação de Antifonte sobre ser a concórdia o maior bem para as cidades. Este conselho, tal como em Hobbes, não era para que os homens fossem tomados por um único pensamento, o que é impossível, mas para que obedecessem às leis apesar de suas divergências. Assim as cidades tornarse-iam prósperas e fortes. Sem a concórdia, nenhum governo poderia existir.

E efectivamente a concórdia parece ser o maior bem para as cidades e nestas, a maior parte das vezes, as assembleias dos anciãos e os homens mais eminentes exortam os cidadãos a viverem em concórdia entre si; e em toda parte, na Hélade, a lei determina que os cidadãos jurem viver em concórdia e em toda parte, prestam este juramento. Julgo que isto sucede não a fim de que elogiem os mesmos tocadores de flauta nem a fim de que elogiem os mesmos poetas nem para que se comprazam com as mesmas coisas, mas que obedeçam às leis. Com efeito, quando os cidadãos Ihes permanecem fiéis, as cidades tornam-se muito fortes e muito prósperas. Mas, sem concórdia, nem a cidade poderia ser governada nem a casa bem administrada (XENOFONTE, apud PINTO, 2005 226). 
Sobre o engenho de Thomas Hobbes em englobar teses conflitantes notamos a presença lógica, ou melhor, antilógica de Antifonte. Seja qual for a escolha do leitor, ou uma monarquia ou uma democracia, haverá sempre unidade e paz em um Estado se houver concórdia em submeter-se ao poder constituído:

Em toda cidade, pela sua origem, destruída a obediência dos cidadãos e por consequência a concórdia, de modo algum florescerão os cidadãos e a cidade em breve tempo dissolverse-á (HOBBES, 1841, 242-243. Tradução nossa). ${ }^{25}$

Assim como em Antifonte, não há uma oposição excludente entre governo de muitos e governo de poucos em Hobbes. Ambos são equivalentes quando se trata da composição do poder, ou seja, pode ser uma ou outra conformação. A partir da antilogia, se o leitor tende à democracia, encontrará razões provenientes deste regime, para obedecer ao poder soberano, e às suas leis, no estado civil. Se por acaso o leitor é partidário da monarquia, ocorre o mesmo, porque o poder pode ser composto por uma assembleia ou um homem. Ambos, portanto, monarquistas e democratas, obedecerão ao soberano porque, ou creem que a doutrina verdadeira é a democracia ou são realistas. Hobbes procura construir no leitor a concórdia e a consequente composição pacífica (ainda que divergentes) da necessária unidade do corpo político. O filósofo inglês construiu argumentos que conquistassem a adesão dos leitores dos dois lados da contenda, de modo a efetivar em quem o lia a sensação de que, ao obedecer ao poder constituído (por democratas ou por monarquistas), seria autor de uma grande obra, o Estado. No Leviatã, o soberano seria o ator, de modo que "se constitui o homem natural em cidadão, o leitor em co-autor" (JANINE RIBEIRO, 1999, 40).

\section{Considerações finais}

Após a apresentação da posição de Espinosa sobre a democracia e a posição ambivalente de Hobbes sobre a democracia e a monarquia, possível graças ao seu dispositivo antilógico, chegamos à estas considerações finais, a partir de nossa hipótese de trabalho, que o pensamento dos filósofos com relação aos regimes políticos não é diametralmente oposto nem excludentes entre si. Esta posição, embora disseminada entre os comentadores, também não é equívoca, pois Hobbes permite esta equivalência perante ao leitor. Chauí $(2003,295)$ é uma das estudiosas de Espinosa que observa 
mais diferenças que semelhanças entre os supracitados. Sobre a democracia e monarquia, afirma a filósofa:

Eis porque, em Hobbes, a ideia de uma assembleia pública e numerosa com funções de governo parece ineficaz e inoperante, seja porque em decorrência do número, jamais chegará a um consenso [...]. Há mais risco de guerra civil neste caso do que num outro defendido por Hobbes: o do monarca governando auxiliado por um pequeno conselho secreto escolhido pelo próprio rei. [...] Espinosa considera que, muito pelo contrário se se desejar a estabilidade política, será preciso multiplicar conselhos e assembleias e fazê-los muito numerosos quanto à quantidade de membros para que "seja impossível corrompê-los" (CHAUÍ, 2003, 294).

Conforme demonstramos, não discordamos em absoluto da interpretação de Chauí, pois ela opta pelo Hobbes monarquista para contrapor seu posicionamento ao de Espinosa. Hobbes, por conta de sua antilogia, permite esta leitura. A única objeção que pode ser feita a este antagonismo ocorre exclusivamente quando não consideramos os textos de Hobbes em sua amplitude e nos restringimos às fontes de Espinosa.

Em uma de suas correspondências endereçadas a Jarigh Jelles, ${ }^{26}$ Espinosa responde sobre sua diferença política entre ele e Hobbes:

Quanto à apreciação política, a diferença entre a minha e a de Hobbes, pela qual interrogas, consiste em que sempre preservo de modo subjacente o Direito natural e que considero que o Magistrado Supremo, em qualquer Cidade, só tem direitos sobre os súditos na medida em que seu poder seja superior ao deles; coisa que sempre ocorre no estado de Natureza (ESPINOSA, 1890, 360. Tradução nossa). ${ }^{27}$

A carta de Espinosa segue tratando de outro assunto, de modo que a diferença apontada de próprio punho se restringe ao entendimento da questão do direito natural. Não há menção sobre a questão da democracia, pois de fato é muito provável que, na leitura de Espinosa, não houvesse divergência neste quesito. Para o holandês, provavelmente Hobbes era um democrata.

A questão do direto natural em ambos os filósofos é complexa, para o qual não adentraremos em profundidade. Somente mencionaremos mais um detalhe sobre este tema que corrobora a leitura de um Hobbes democrata por parte de Espinosa. 
Em Espinosa, a natureza, ou ainda, o direito natural, permanece subjacente no Estado Civil. Isso ocorre, segundo Chauí (2003, 301), em função de sua noção de causa eficiente. De modo muito generalizante, isso equivale a afirmar que, como a natureza é Deus em Espinosa, a causa eficiente no mundo é imanente, ou seja, a causa primeira permanece em todos seus efeitos. Já em Hobbes a causa eficiente não possui este caráter imanente, ela importa somente com relação à sua cadeia de efeitos aparentes ou inversamente, dos efeitos às causas. ${ }^{28}$ Não importa, para Hobbes, qual a origem primeira desta causa eficiente, somente até o elo necessário que permita a reprodução dos efeitos ou em que seja possível reconhecer as causas de um fenômeno. Chauí afirma que, por este motivo, a democracia é importante para Espinosa, pois está mais enraizada e mais próxima de sua causa imanente, pois assim como em Hobbes, a democracia é o primeiro momento da vida política. O primórdio do Estado Civil é o conjunto de homens concordando entre si sobre alguma convenção. A diferença, entre os filósofos, ocorre também neste ato: em Hobbes, pela falta da imanência e pela força da convenção artificial, 29 "a criatura tem autonomia com relação aos seus criadores" (Ibidem). Concordamos com Chauí neste ponto, sobretudo porque o contrato de Espinosa se dá entre soberano e súditos, enquanto em Hobbes se dá entre os súditos que abrem mão do direito de governarem a si próprios em favor do soberano (uma assembleia ou um monarca), que ganha plena autonomia.

Cedo e transfiro meu direito de governar-me a mim mesmo a este homem, ou a esta assembléia de homens, com a condição de transferires a ele teu direito, autorizando de maneira semelhante todas as suas ações. Feito isto, à multidão assim unida numa só pessoa se chama Estado, em latim civitas (HOBBES, 1997, 144)

Afirma a filósofa que é sobre esta diferença que o holandês aponta a Jelles, sobre a "permanência da causa no efeito que a exprime de maneira determinada esclarece porque 0 direito natural permanece bem resguardado no direito civil, uma vez que este é o direito natural coletivo." (CHAUI, 2003, 302).

Ocorre que, o argumento da autonomia em seu sentido estrito, do auto nómos (aquele que atribui a si próprio as suas leis), um subsídio ideológico para uma monarquia absolutista em Hobbes, a partir da antilogia, possibilita-nos igualmente pensar o seu contrário, uma democracia absoluta autônoma. Em outras palavras, o soberano autônomo, afinal, abriu uma possibilidade até então inexistente: a criação de um mundo inteiramente 
outro. Pela primeira vez na história da filosofia política, um filósofo afirmou ser possível libertar-se das amarras das leis naturais, a partir das leis naturais. A terceira lei de natureza de Hobbes nos manda respeitar os pactos celebrados. ${ }^{30}$ Cumprir os pactos significa que qualquer coisa pode ser instituída a partir de então, desde que os pactuantes concordem em obedecer ao soberano, que pode ser uma assembleia ou um monarca. Não há, em Hobbes, nenhum impedimento acerca da matéria sobre a qual se celebram os pactos, nem mesmo se verdadeira ou não. Por este motivo, a filosofia de Hobbes é também a promessa e a esperança de um novo Estado, de um novo pacto, feito exclusivamente pelas mãos dos homens.

Os dizeres hobbesianos sobre os homens e suas leis, segundo Davenant inspiraram os levellers, sobretudo porque seu soberano, que poderia ser uma assembleia de homens, era o detentor absoluto do poder do Estado através de suas leis. Se por um lado, isso foi lido como uma doutrina totalitária por Arendt $(1998,174)$, entre outros, por outro pôde soar de modo libertador na medida em que se interpretou a soberania de Hobbes como uma filosofia potencialmente promotora de uma nova criatura política. Em outras palavras, isto representou um novo estado artificial de coisas que, nas mãos dos levellers e de Van den Enden, poderia ser inteiramente edificada de modo equitativo, pois a democracia hobbesiana, assim como a monarquia, subsiste em uma soberania absoluta. A assembleia democrática é absoluta em Hobbes, assim como em Espinosa, que afirma sobre o Estado conduzido por uma assembleia ser "inteiramente absoluto e a que chamamos democrático." (ESPINOSA, 1973, 371)

A filosofia política de Hobbes possibilitou, às democracias nascentes do século $X X$, a criação de um mundo inteiramente outro. Trata-se do mecanismo jurídico que permitiu as inovações em nossas legislações. Se hoje há leis que permitem a alteração de sexo biológico ou o sufrágio universal, isto se deveu à autonomia do soberano (pela via da assembleia) na criação de suas leis. O que fundamenta a lei, em Hobbes, é a própria lei.

A invenção das leis é de responsabilidade do soberano (uma assembleia ou um monarca) e não mais de um ente divino. Como constatou Bobbio, Hobbes inventou a concepção de justiça formal, pela qual só existe injustiça no Estado Civil. É "justo o que é ordenado por quem tem o poder de ordenar e injusto o que é proibido, pelo fato de ser proibido." (BOBBIO, $1991,103)$. Por este motivo, ainda segundo Bobbio, Hobbes é o pai do positivismo jurídico (BOBBIO, 1991, 102), ou seja, o criador do império das leis. Trata-se de uma concepção legalista de justiça derivada de um ditame da lei natural. A filosofia de Hobbes foi, portanto, nas mãos de mentes desejosas em revolucionar o mundo no século XVII, na Holanda ou na 
Inglaterra, uma das obras mais inspiradoras e libertadoras até então escrita. 


\section{Notas}

1 Possui graduação em Ciências Sociais pela Faculdade de Filosofia, Letras e Ciências Humanas da USP , mestrado e doutorado pela USP em Ética e Filosofia Política. Atualmente é professora adjunta e pesquisadora na Universidade Federal da Integração Latino-Americana. (UNILA).

2 Marilena Chauí, em seu estudo sobre as diferenças e semelhanças entre Espinosa e Hobbes, aponta para esta questão, opondo-os neste quesito $(2003,294)$. Muitos outros comentadores seguirão o mesmo caminho.

3 São as obras de Lambertus van Velthuyesen que dão início ao cartesianismo holandês político, também denominado pela autora como Cartesianismo Radical Holandês (NYDEN-BULLOCK, 2007, 7).

4 Na edição de Van Vloten e Land, encontramos duas cartas endereçadas a Van Velthuyesen, a XLII (ESPINOSA, 1890, 336) e a LXIX (ESPINOSA, 1890, 405).

${ }^{5}$ Nesta ocasião Espinosa tinha 24 anos.

${ }^{6}$ Pieter Cornelisz Plockhoy (1625, possivelmente em Zierikzee, Holanda - c. 16641670, Delaware, EUA), foi autor de $A$ Way Propounded to Make the Poor in these and other Nations Happy (Uma proposta para tornar felizes os pobres nestas e em outras nações). Tentou dar vazão à sua utopia através de um assentamento, mas em um ano foi derrotado pela armada inglesa. Foi um menonita crítico de sua religião.

Disponível

em:

https://gameo.org/index.php?title=Plockhoy, Pieter Cornelisz (1620\%3F-

1700\%3F). Acesso em: 01 out. 2021.

${ }^{7}$ In case we want to keep ourselves to the first principles, we first have to examine whether they are good and agree with the principles of the evenequal freedom; but if not, we may destroy them all very readily, lightly and to our greatest profit: because no calmly and competently economizing citizen will ever be found to be so dull or stupid, that he would not, in case it was well proposed to him, prefer to help annihilating everything which opposes the principles of the evenequal Freedom. And this I take not only for the only right medicine of all civil evils, but also for the exclusive unshakable firm ground of an eternal empire (eeuwigdurende Politie) or commonwealth (gemeen beste).

${ }^{8}$ Nam, si, dum Romani deliberant, perit Sagunthus; dum contra pauci ex solo suo affectu ominia decernunt, perit libertas commune que bonum.

9 Optamos por traduzir do latim as passagens do Tratado Político aqui utilizadas pois as traduções em língua portuguesa não mantêm o termo multidão, optando traduzir este termo por povo. Consideramos isso um problema quando se pretende compreender a manutenção da liberdade do estado de natureza, pois a figura política do Populi não é a mesma que a multidão. A multidão é forma livre, o sujeito 
político que se mantem desde o estado de natureza até o estado civil na filosofia política de Espinosa. Não é fortuito o emprego desta palavra por Espinosa.

10 Concludimos itaque, multitudinem fatis amplam libertatem sub Regem servare posse, modo efficiat, ut Regis potentia sola ipsius multitudinis potentia determinetur, et ipsius multitudinis praesidio servetur. Arque haec única fuit Regula, quam in jaciendis Imperiii Monarchici fundamentis sequutus sum.

${ }^{11}$ O Tratado Político foi uma obra póstuma e não foi concluída por Espinosa.

12 No Tratado Político Espinosa faz uma descrição do que ele entende por regime democrático; "Passo agora ao terceiro Estado, que é inteiramente absoluto e a que chamamos democrático. A diferença entre este Estado e o aristocrático consiste, principalmente, já o dissemos, em que, neste último, depende unicamente da vontade e da livre escolha da assembléia suprema que este ou aquele se torne patrício; ninguém tem, portanto, hereditariamente, o direito de sufrágio e o de aceder às funções públicas. Ninguém pode reivindicar os seus direitos, como é o caso numa democracia. Todos aqueles, com efeito, que nasceram de pais no gozo dos seus direitos cívicos, ou no território nacional, ou que souberam merecer a República, ou que, por outras causas ainda, possuem legalmente o direito de cidadania, todos, repito, têm direito de sufrágio e acesso às funções públicas; podem reclamar os seus direitos e não se lhos pode negar senão por se terem tomado culpados de um crime, ou marcados de infâmia." (ESPINOSA, 1973, 371).

13 Oliver Cromwell foi o principal comandante do Exército Novo (New Model Army) que derrotou as forças realistas da Inglaterra no período da Guerra Civil Inglesa. Após isso foi nomeado como o primeiro Lord Protector do Protetorado, no período 1653-1659.

${ }^{14} \mathrm{All}$ honest men here are very glad that the King hath at length banished from his court that father of atheists Mr. Hobbes.

${ }^{15}$ Conde de Clarendon, cujo nome era Edward Hyde, escreveu uma History, sendo este um dos documentos mais importantes sobre a Guerra Civil Inglesa. Segundo Aylmer, o Conde estava do lado do Rei, era basicamente um realista, mas, por outro lado, defendia uma monarquia constitucionalista e não uma monarquia absoluta (Aylmer, 1963, 12). Aylmer prescreve cuidado ao se tomar as edições decupadas da Oxford, porque, além de considerar o povo como o parlamento (havia populares ao lado do Rei, mas não parlamentares), as passagens omitem as qualidades da historiografia de Clarendon, que conhecia a matéria. Sobre o conflito ideológico entre parlamento e Rei, os textos concentravam-se entre a Lei Comum e a Magna Carta contra o Direito Divino dos Reis. (ARRUDA, 2006, 56).

16 Este texto foi publicado pela primeira vez em 1650 como um prefácio a um inacabado poema heroico de autoria de Davenant, intitulado Gondibert an heroick Poem. Quando finalizado, o editor publicou, além do ataque a Hobbes, a réplica de Hobbes e, na sequência, o poema na íntegra. Conferir edição de Davenant (1651). 
${ }^{17}$ Hobbes assinala em seu Leviatã que a existência de ligas entre súditos, quando há um poder soberano, recebe geralmente "o nome de facção ou conspiração" (1997, II, XXI, 188). Mas na ausência de um poder soberano, são benéficas e promovem a defesa mútua. No caso de liga entre Estados, por exemplo, "não apenas são legítimas como também proveitosas durante o tempo em que duram" (HOBBES, 1997, 188).

18 Hobbes trata dos mais diferentes tipos de convenções no Leviatã em: Parte I (Introdução, XII, XIV, XV, XVI). Parte II (XVII, XVIII, XX, XXI, XXII, XXV, XXVI, XXVII, XXVIII, XXX, XXXI). Parte III (XXXIII. XXXIV, XXXV, XXXVIII, XL, XLI, $\mathrm{XLII})$.

19 That very entering into the Covenant with the Scottish nation against the King, is by itself a very great crime, and you [Thomas Hobbes] guilty of it. And so was the imposing of the Engagement, and you guilty of that also, as being done by the then Parliament, whose democratical principles you approve of.

20 Tout ce que ie puis dire du livre De Cive, est que ie iuge que son autheur est le mesme que celuy qui a fait les troisièmes Obiections contre mês Meditations, \& que ie le trouve beaucoup plus habile en Morale qu'en Metaphysique ny en Physique; nonobstants que ie ne puisse aucunement aprouver ses principes ny ses maximes, qui sont tres-mauvaises et tres-dangereuses, en ce qu'il suppose tous les hommes méchans, ou qu'il leur donne sujet de l'estre. Tout son but est d'ècrire en faveur de la Monarchie.

${ }^{21}$ Esta seção é baseada nos estudos sobre a Antilogia em Hobbes de Nakayama (2016, 129-140).

22 A doxografia atesta como certa esta relação de mestre e discípulo: "Com efeito, ouço muitos dizendo que Tucídides foi aluno de Antifonte de Ramnunte" (Hermógenes, De ideis, 2, 11 [A.2 DK]); "[Sobre Antifonte] Diz-se ter sido professor de Tucídides" (Suda S.v. Antiphôn (a2744-46, 1.245 Adler) [A.1 DK/ A.1 U/ T3 P]; "Cecilio, em sua obra sobre Antifonte, assevera que Tucídides foi seu aluno" Pseudo-Plutarco (Vitae decem oratorum A.6 DK). Todas as passagens foram traduzidas por Bellintani Ribeiro (ANTIFONTE, 2008, 27-28 e 33).

${ }^{23}$ Antifonte de Ramnunte (480 a.C.- 411 a.C.). É considerado o mais antigo dos dez oradores áticos. Era aristocrata e produziu três discursos judiciários e obras relativas ao ensinamento da eloquência. Também escreveu modelos de exórdios, perorações e um texto chamado "Sobre a verdade", do qual analisaremos alguns fragmentos mais adiante. Pertence à geração de Górgias e dos primeiros sofistas. Foi mestre de retórica e logógrafo. Participou ativamente da conjuração dos Quatrocentos (a conjuração contra o governo democrático), sendo considerado por muitos, seu mentor intelectual. Foi condenado à morte em 411 quando a democracia retorna seu efêmero poder na Magna Grécia, que durou somente um ano. (SMITH, 1859, 206-207).

${ }^{24}$ Hobbes (1966) traduziu a Guerra do Peloponeso de Tucídides em 1629 para o inglês. Trata-se de uma tradução de suma importância para os estudiosos da obra 
até nossos dias pois foi a segunda elaborada direta do grego. A tradução de Hobbes pode ser encontrada no English Works of Thomas Hobbes, volume VIII e IX.

${ }^{25}$ Ut veniam jam ad doctrinas particulares quas populos docendus est, prima erit, ne formas regiminis, quas in gentibus vicinis conspiciunt, plusquam formam civitatis propriae adament, aut imitari cupiant, quamtamcumque gentium illarum prosperitatem videant. Non enim ab aristocratia, vel democratia, aut monarchia, sed ab obedentia et concordia civium in quacunque civitate res secundae oriuntur. In omni civitatis gerere, sublata obedientia, et proinde concordia, civium, non modo non florebunt cives, sed civitas brevi tempore dissoveltur.

${ }^{26}$ Epístola L (ESPINOSA, 1890, 360).

27 Quantum ad Politicam spectat, discrimen inter me et Hobesium, de quo interrogas, in hoc consistit, quod ego naturale Jus semper sartum tectum conservo, quodque Supremo Magistratui in qualibet Urbe non plus in subditus juris, quam juxta mensuram potestatis, qua subditum superat, competere statuo, quo in statu Naturali semper locum habet.

${ }^{28}$ Segundo Hobbes, a filosofia "é o conhecimento dos efeitos ou aparências, que adquirimos raciocinando corretamente a partir do conhecimento que temos inicialmente de suas causas ou geração; bem como [o conhecimento] de quais podem ser essas causas ou gerações, a partir do conhecimento de seus efeitos." (HOBBES, 2005, 8).

${ }^{29}$ Afirma Hobbes "Por último, o acordo vigente entre essas criaturas é natural, ao passo que o dos homens surge apenas através de um pacto, isto é, artificialmente. Portanto não é de admirar que seja necessária alguma coisa mais, além de um pacto, para tornar constante e duradouro seu acordo: ou seja, um poder comum que os mantenha em respeito, e que dirija suas ações no sentido do benefício comum." (HOBBES, 1997, 143)

30 "Que os homens cumpram os pactos que celebrarem e mais adiante que nesta lei reside a fonte e a origem da justiça." (HOBBES, 1997, 123). 


\section{Referências bibliográficas}

ANTIFONTE. Testemunhos, fragmentos, discursos - edição bilíngue. Tradução: Luís Felipe Bellintani Ribeiro. São Paulo: Edições Loyola, 2008.

AYLMER, G. E. A short history of 17th century England: 1603-1689. New York: The New American Library/ Blandford Press, 1963.

ARENDT, H. Origens do totalitarismo. São Paulo: Companhia das Letras, 1989.

ARRUDA, J. A Revolução Inglesa. São Paulo: Brasiliense, 2006.

BOBBIO, N. Thomas Hobbes. Torino: Giulio Einaudi. Tradução: Carlos Coutinho. Rio de Janeiro: Campus, 1991.

CHAUÍ, M. Política em Espinosa. São Paulo: Companhia das Letras, 2003.

DAVENANT, W. Gondibert an heroick poem. London: Printed by John Holden, 1651.

DAVENANT, W. Considerations upon the reputation, loyalty, manners, and religion of Thomas Hobbes. In: The english works of Thomas Hobbes of Malmesbury, vol. IV. London: W. Molesworth ed., 1966.

ESPINOSA, B. Opera Quotquot Reperta Sunt. Tomo I. Recognoverunt Van Vloten, J. e LAND, J.P.N. Hagar Comitum: Martinum Nijhoff, 1882.

ESPINOSA, B. Opera Quotquot Reperta Sunt. Tomo II. Recognoverunt Van Vloten, J. e Land, J.P.N. Hagar Comitum: Martinum Nijhoff, 1890.

ESPINOSA, B. Tratado teológico político. Tradução: Aurelio, D.P. Lisboa: Imprensa Nacional Casa da Moeda: 2004.

ESPINOSA, B. Tratado político. In: Os pensadores - Baruch de Espinosa. Tomo XVII. São Paulo: Abril Cultural. 1973.

GAGARIN, M. The truth of Antiphon's truth. In: Essays in Ancient Greek Philosophy VI Before Plato. Edited by Anthony Preus. New York: State University of New York Press, 2001.

GOOCH, G. P. Hobbes. London: Humphrey Milford, 1939. 
HOBBES, T. Do cidadão. Tradução: Renato Janine Ribeiro. São Paulo: Martins Fontes, 1998.

HOBBES, T. Elementos do direito natural e político. Tradução: Couto, F. Porto-Portugal: Resjurídica, 19--.

HOBBES, T. Elementos de filosofia - primeira seção - sobre o corpo. Parte I - Computação ou Lógica. In: Clássicos da Filosofia. Cadernos de Tradução 12. Tradução: José Oscar de A. Marques. Campinas: IFCH/Unicamp, 2005.

HOBBES, T. The History of the grecian war written by Thucidides. In: English works of Thomas Hobbes, vol. VIII. London: W. Molesworth ed., 1966.

HOBBES, T. Leviatã ou matéria, forma e poder de um estado eclesiástico e civil. Tradução: João Paulo Monteiro. São Paulo: Nova Cultural, 1997.

HOBBES, T. Leviathan sive de materia, forma, et potestate civitatis ecclesiasticae et civilis. In: Opera philosophica quae latine scripsit omnia, vol. III. Londres: Joannem Bohn. 1841

NAKAYAMA, P. La antilogía en el iuspositivismo y el iusnaturalismo de Thomas Hobbes. In: Las Torres de Lucca, International Journal of Political Philosophy, Madrid, Universidad Complutense de Madrid, no 9, p. 119-144, Julio-Diciembre, 2016.2 Disponível em: https://revistas.ucm.es/index.php/LTDL/article/view/76983. Acesso em: 01 out. 2021

JANINE RIBEIRO, R. Ao leitor sem medo: Hobbes escrevendo contra o seu tempo. Belo Horizonte: UFMG, 1999.

KLEVER, W. A New Source of Spinozism: Franciscus van den Enden. In: Journal of the History of Philosophy, Berkeley (Calif.), t. 29/4, p. 613-631, 1991.

KLEVER, W. Imperium Aeternum. Spinoza's Critique of Machiavelli and Its Source in van Den Enden. In: Foglio Spinoziano, 2016.

MALCON, N. Hobbes and Spinoza. In: Aspects of Hobbes. Oxford Scholarship Online (OSO): Oxford University Press, 2008.

NYDEN-BULLOCK, Tammy. How Hobbes got to Spinoza: A Radical Cartesian Journey. In: Early Modern Philosophy in Britain and the Netherlands 15001800: British Society for the History of Philosophy Conference, Rotterdam, 
The Netherlands. Mar 2007. Disponível em: https://philarchive.org/archive/NYDHHG. Acesso em 01 out. 2021. PINTO, M. (Ed.). Sofistas - testemunhos e fragmentos Tradução: Ana Alexandre A. de Souza e Maria José Vaz Pinto. Lisboa: Imprensa Nacional Casa da Moeda, 2005.

SCHMITT, C. The leviathan in the state theory of Thomas Hobbes: meaning and failure of a political symbol. Chicago: University Chicago Press, [2008] 1938.

SCHUHMANN, K. Hobbes, une chronique: cheminement de sa pensée et de sa vie. Paris: J. Vrin, 1998.

SMITH, W. Dictionary of greek and roman antiquities. Boston: Little, Brown and Company, 1859.

TREVOR-ROPER, H. Thomas Hobbes. In: Historical Essays. London: Macmilian, 1957.

VIALATOUX, J. La cité totalitaire de Hobbes. Lyon: Chronique sociale de France, 1952.

VIDAL, G. Oratoria griega y oradores áticos del primer periodo (de fines del siglo $\mathrm{V}$ a inícios del siglo IV a. C.). México: Universidad Nacional Autônoma de México, 2004.

VIDAL, G. Humanismo y cosmopolitismo en Antifonte. In: Habis, 29, p. 37$50,1998$.

WATKINS, J. W. N. Hobbes's system of ideas. London: Hutchinson, 1965. 